\title{
KONSEP KESEHATAN DALAM AL-QUR'AN DAN HADIS
}

\author{
Diong Liong Akbar \\ Diongliongakbar4444@gmail.com \\ Budiyanto \\ budiyanto3781@gmail.com
}

\begin{abstract}
Abstrak
Dalam kehidupan manusia, kesehatan merupakan salah satu aspek primer yang perlu mendapat perhatian sejajar dengan aspek kehidupan primer lain seperti aspek pendidikan maupun aspek ekonomi. Dalam konsep Ad-Dhoruriyyat atau maqashid syari'ah yang dikemukakan Al-Ghazali, aspek kesehatan memperoleh tempat dan masuk dalam Hifdz An-Nafs (memelihara jiwa). Hal ini menunjukkan bahwa manusia harus memelihara jiwanya dari beberapa macam gangguan seperti musuh atau dalam hal ini memelihara jiwa dari berbagai macam penyakit yang dapat dilakukan melalui aspek kesehatan. Dalam memelihara jiwa melalui aspek kesehatan, manusia tidak lantas tanpa aturan dan arahan. Dalam hal ini, Al-Qur'an telah memberikan gambaran bagaimana seharusnya manusia memelihara kesehatannya. Tujuan dari penelitian ini adalah mengetahui pengertian kesehatan sekaligus bagaimana memelihara kesehatan sesuai dalam Konsep Al-Qur'an Hadis yang diperoleh melalui metode kajian pustaka. Hasil dari penelitian ini menunjukkan bahwa banyaknya ayat Al-Qur'an dan riwayat Hadits tentang kesehatan menunjukkan bahwa manusia diperintah untuk memberikan perhatian lebih terhadap hal-hal yang berkaitan dengan kesehatan dalam rangka ikhtiar diri untuk menjalankan rangkaian ibadah kepada Allah.

Keywords: Konsep, Kesehatan, Al-Qur'an dan Hadis
\end{abstract}

Sekolah Tinggi Ilmu Al Qur'anWali Songo Situbondo

\section{Pendahuluan}

Manusia diciptakan di dunia ini untuk menjadi khalifah dan beribadah kepada Allah Subhanahu Wata' Ala sesuai dengan konsep Al Qur'an maupun hadis Namun, kedua fungsi tersebut tidak akan bisa terlaksana dengan baik, tanpa adanya kesehatan yang dimiliki oleh setiap manusia. Melihat pentingnya kesehatan tersebut, islam memiliki pandangan (perspektif) tersendiri tentang kesehatan.

Berdasarkan kedudukannya, Alquran dan Hadist sebagai pedoman hidup dan sumber ajaran Islam, antara satu dengan yang lainnya jelas tidak dapat dipisahkan. Alquran sebagai sumber pertama memuat ajaran-ajaran yang bersifat umum, yang perlu dijelaskan lebih lanjut dan terperinci. Di sinilah Sunnah menduduki dan menempati fungsinya sebagai ajaran kedua. Sunnah Nabi muhammad Shollahu Alaihi Wasallam menjadi penjelas bagi Alquran. ${ }^{1}$ Dan juga Al-Qur'an dan hadist yang merupakan pedoman hidup bagi orang-orang yang beriman banyak menjelaskan hal-hal yang berkaitan dengan kesehatan, baik itu berupa perintah, anjuran, ataupun larangan.

\footnotetext{
${ }^{1}$ Budiyanto, B. (2020). Sikap Ilmiah Terhadap Urgensi Hadis Dalam Pendidikan Agama Islam. Al-Bayan: Jurnal Ilmu Al-Qur'an Dan Hadist, 3(1), 34-46. https://doi.org/10.35132/albayan.v3i1.83
} 
Banyaknya penjelasan yang terdapat dalam kedua pedoman hidup ini seakan-akan menunjukkan bahwa betapa pentingnya sebuah arti kesehatan bagi seorang manusia. ${ }^{2}$

Oleh karena itu, dalam Jurnal yang merupakan rangkuman dari berbagai referensi ini akan dijelaskan tentang pandangan (perspektif) islam terhadap kesehatan. Dalam Jurnal ini juga akan dijelaskan beberapa ayat al-Qur'an dan hadist yang menerangkan tentang kesehatan. Dengan Jurnal ini, diharapakan kita bisa memahami arti sebuah kesehatan dalam konsep islam dengan study al qur'an dan munasabahnya dengan hadits. Islam menetapkan tujuan pokok kehadirannya untuk memelihara agama, jiwa, akal, jasmani, harta, dan keturunan. Setidaknya tiga dari yang disebut di atas berkaitan dengan kesehatan. Tidak heran jika ditemukan bahwa Islam amat kaya dengan tuntunan kesehatan.

Paling tidak ada dua istilah literatur keagamaan yang digunakan untuk menunjuk tentang pentingnya kesehatan dalam pandangan Islam, yaitu: Kesehatan yang terambil dari kata sehat dan Afiat. Keduanya dalam bahasa Indonesia, sering menjadi kata majemuk sehat afiat. Dalam Kamus Besar Bahasa Indonesia, kata "afiat” dipersamakan dengan kata "sehat". Afiat diartikan sehat dan kuat, sedangkan sehat sendiri antara lain diartikan sebagai keadaan segenap badan serta bagian-bagiannya (bebas dari sakit).Tentu pengertian kebahasaan ini berbeda dengan pengertian dalam tinjauan ilmu kesehatan, yang memperkenalkan istilah-istilah kesehatan fisik, kesehatan mental, dan kesehatan masyarakat. $^{3}$

Istilah sehat dan afiat masing-masing digunakan untuk makna yang berbeda , kendati diakui tidak jarang hanya disebut salah satunya, karena masing-masing kata tersebut dapat mewakili makna yang dikandung oleh kata yang tidak disebut. Dalam literatur keagamaan, bahkan dalam hadits-hadits Nabi saw. Ditemukan sekian banyak do'a, yang menagandung permohonan afiat, disamping permohonan memperoleh sehat.Dalam kamus bahasa Arab, kata afiat diartikan sebagai perlindungan Allah untuk hamba-Nya dari segala macam bencana dan tipu daya. Perlindungan itu tentunya tidak dapat diperoleh secara sempurna kecuali bagi mereka yang mengindahkan petunjuk-

\footnotetext{
${ }^{2}$ Ali Nurdin. Kesehatan dalam Konsep `(Slide Kuliah 1/10/2012). Jakarta; 2012. Hal 15

${ }^{3}$ Acmad Gholib. Study Ialam: Belajar memahami Agama, Al-Qur'an, AL-Hadist, dan sejarah peradaban Islam. Jakarta: Faza Media; 2005. 135
} 
petunjuk-Nya. Maka kata afiat dapat diartikan sebagai berfungsinya anggota tubuh manusia sesuai dengan tujuan penciptaannya.Kalau sehat diartikan sebagai keadaan baik bagi segenap anggota badan, maka agaknya dapat dikatakan bahwa mata yang sehat adalah mata yang dapat melihat maupun membaca tanpa menggunakan kaca mata. Tapi, mata yang afiat adalah yang dapat melihat dan membaca objek-objek yang bermanfaat serta mengalihkan pandangan dari objek-objek yang terlarang, karena itulah fungsi yang diharapkan dari penciptaan mata.

\section{Metodologi}

Adapun metode dari Jurnal ini adalah menggunakan Metode kepustakaan atau kajian pustaka ( Library research) yaitu sumber data yang didapat dari buku-buku ilmiah, jurnal, penulis menganalisis, menyimpulkan serta memahami data-data yang ada sebagai bahan utama pembuatan jurnal sesuai dengan topik yang penulis bahas dalam jurnal ini.

\section{Pembahasan}

\section{A. Konsep kesehatan dalam Al-Qur'an dan Hadis}

Al-Qur'an yang merupakan kitab yang diturunkan Allah kepada Nabi Muhammad Shollahu Alaihi Wasallam bukan merupakan sesuatu yang sia-sia atau tanpa maksud dan fungsi yang jelas. Al-Qur'an diturunkan dengan berbagai fungsi dan maksud tertentu. Menurut Dr. M. Quraish Shihab, Al-Qur'an diturunkan dengan banyak fungsi, diantaranya sebagai bukti kebenaran Nabi Muhammad Shollahu Alaihi Wasallam . bukti kebenaran tersebut dibuktikan dalam tantangan yang bersifat bertahap. Pertama, menantang siapa yang meragukan untuk menyusun semacan al-Quran secara keseluruhan (QS. 52:34). Kedua, menantang mereka untuk menyusun sepuluh surah semacam al-Qur'an (QS. 11:13). Ketiga, menantang mereka untuk menyusun satu surah yang semisal surah dalam al-Qur'an (QS. 10:38). Keempat, menantang mereka untuk menyusun satu surah semisal surah dalam al-Qur'an dengan bantuan siapapun selain Allah (QS. 2:23). Fungsi lain dari al -Qur'an adalah sebagai petunjuk bagi manusia seperti dijelaskan dalam al-Qur'an yang berbunyi ${ }^{4}$ :

\footnotetext{
${ }^{4}$ Achmad Ghalib. Kuliah Kesehatan dalam Persfektif Islam (Slide Kuliah 26/09/2012). Jakarta: 2012.hal 40
} 


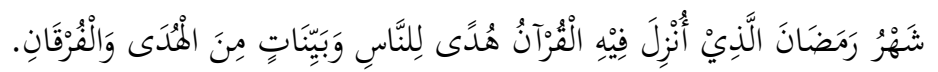

Artinya:

"Bulan Ramadan adalah (bulan) yang di dalamnya diturunkan Al-Qur'an, sebagai petunjuk bagi manusia dan penjelasan-penjelasan mengenai petunjuk itu dan pembeda (antara yang benar dan yang salah)”. (QS. Al-Baqarah $2: 185)$.

Selain sebagai petunjuk (huda), al-Qur'an juga berfungsi sebagai pembeda antara yang benar dan yang salah (furqan), penerang jalan hidup (bayyinah), penyembuh penyakit hati (syifa), sumber informasi (bayan), dan nasehat atau petuah (Mauizhah). salah satu fungsi al-Qur'an adalah sebagai huda (petunjuk), petunjuk alQur'an bersifat luas dan meliputi seluruh aspek kehidupan, baik tentang kehidupan duniawi ataupun kehidupan ukhrawi. Salah satu yang menjadi topiuk pembicaraan dan menjadi hal yang diperhatikan oleh al-Qur'an adalah tentang kesehatan.

Kesehatan dalam al-Qur'an diungkapkan dalam berbagai istilah, hal ini menunjukkan kekayaan bahasa yang dimikili oleh bahasa Arab umumnya, dan alQur'an khususnya. Diantara istilah tersebut adalah ;

شَفَاءٌ berbunyi :

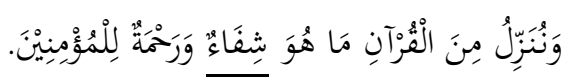

Artinya

"Dan Kami turunkan dari Al-Qur'an (sesuatu) yang menjadi penyembuh dan rahmat bagi orang yang beriman”. (QS. Al-Isra'/17; 82).

As-syifa secara bahasa diartikan sebagai sebagai suatu keadaan yang mendekati pada sesuatu, dan pada umunya diartikan sebagai kesembuhan karena mendekati pulih seperti sebelum sakit.

Ayat di atas menerangkan allah menurunkan al qur'an sebagai obat penyembuh nagi kita sekalian baik secara rohani dan jasmani yang mana hati yang kotor fikiran yang jelek serta jasmani yang tak sehat al qur'anla sebagai solusinya penyembuh dohir dan batin dan juga obat bagi orang-orang mukmin. Fungsi penciptaan manusia di dunia 
untuk menjadi khlafah di muka bumi dan beribadah kepada Allah. Namun, dua fungsi penciptaan manusia ini tidak akan terwujud dengan sempurna tanpa adanya kesehatan yang mendukungnya.

Kata as-shihah dan al-afiyah tidak hanya disebutkan dalam al-Qur'an. Namun, juga sering disebutkan dalam hadist dan do'a-do'a diantaranya:

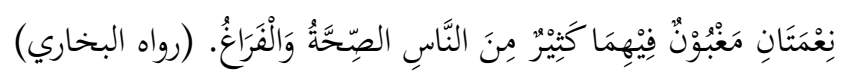

"Dua kenikmatan yang banyak manusia menjadi rugi (karena tidak diperhatikan), yaitu kesehatan dan waktu luang”. (HR. Al-Bukhari)

Dan juga dalam do'a yang dibaca ketika duduk diantara dua sujud, yang berbunyi:

"Dan anugerahkan kesehatan padaku”

Kalimat yang terdapat dalam do'a qunut:

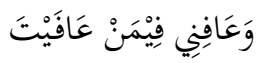

"Dan anugerahkan kesehatan padaku sebagaimana oran yang kau beri kesehatan"

\section{B. Pengertian Sehat}

Sehat biasanya diartikan sebagai suatu keadaan yang baik bagi seluruh anggota tubuh, dan dapat menjalankan fungsinya. Dalam Munjid al-Thulab, Fu'ad Ifram alBustamy berpendapat bahwa sehat adalah hilangnya penyakit, dan berarti pula sesuatu yang terbebas, dan selamat dari segala yang tercela.

Kesehatan biasanya juga mempunyai dua pengertian, yaitu kesehatan jasmani yang kemudian diistilahkan dengan kata as-shihah, dan kesehatan rohani yang diistilahkan dengan kata afiat. Dalam Kamus Besar Bahasa Indonesia, kata afiat dipersamakan dengan kata as-shihah. Afiat diartikan sebagai sehat dan kuat, sedangkan as-shihah diartikan sebagai keadaan baik pada segenap badan serta bagian-bagiannya bebas dari sakit. Jadi, dapat disimpulkan bahwa sehat merupakan lawan dari sakit, dan 
afiat diartikan sebagai sehat yang sempurna (al-shihah al-tammah) dan berati pula kuat dan tegap. ${ }^{5}$

Pengertian sehat sesuai dengan UU No. 23 tentang Kesehatan adalah keadaan sejahtera dari badan, jiwa, dan sosial yang memungkinkan setiaporang hidup produktif secara sosial dan ekonomis. Terkait tenteng hal tersebut, al-Qu'an juga mempunyai istilah-istilah tersendiri dalam mengungkapkan istilah kata kesehatan.

\section{Pola Hidup Sehat Menurut Al-Qur'an}

Al-Qur'an mengajarkan kepada manusia agar selalu berusaha mendapatkan kebaikan dalam hal dunia, ataupun dalam hal akhirat. Hal ini dibuktikan dengan firman Allah yang berbunyi:

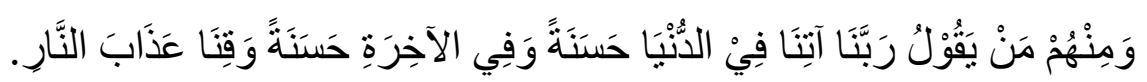

Dan di antara mereka ada yang berdoa, "Ya Tuhan kami, berilah kami kebaikan di dunia dan kebaikan di akhirat, dan lindungilah kami dari azab neraka." (QS. Al-Baqarah (2); 201).

Salah satu unsur kebaikan dunia adalah kesehatan. Oleh karena itu, kita harus berusaha menjaga kesehtan yang ada, dan mengembalikannya ketika kesehatan itu hilang $^{6}$

\section{Ayat-Ayat Tentang Kesehatan}

Islam sangat memperhatikan tentang masalah kesehatan. Hal ini terbukti banyaknya ayat-ayat al-Qur'an dan hadist yang memerintahkan manusia untuk hidup sehat, diantaranya:

a. Kebersihan diri

Istilah kebersihan dalam al-Qur'an dicantumkan dengan Thaharah (kesucian atau kebersihan), kata tersebut disebutkan dalam al-Qur'an sebanyak 31 kali. Diantaranya ${ }^{7}$ :

\footnotetext{
${ }^{5}$ Ali Nurdin. Kesehatan dalam Konsep ` (Slide Kuliah 1/10/2012). Jakarta; 2012. Hal 12

${ }^{6}$ Achmad Ghalib. Kuliah Kesehatan dalam Persfektif Islam (Slide Kuliah 26/09/2012). Jakarta: 2012. Hal 
“Dan pakaianmu bersihkanlah". (QS. Al-Mudatstsir/74; 4)

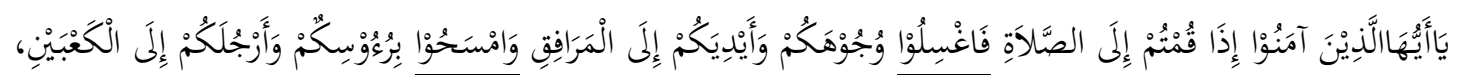

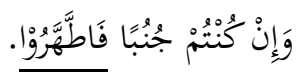

"Wahai orang-orang yang beriman. Bila kamu hendak melaksanakan salat, maka basuhlah wajahmu dan tanganmu sampai siku, dan sapulah kepalamu, dan (basuh) kedua kakimu sampai mata kaki. Jika kamu junub maka bersihkanlah (dengan mandi) "'(QS. Al-Ma'idah/5:6).

Dalil tersebut diatas menyuruh manusia untuk terus membersihkan diri, ini sesuai dengan konsep kesehatan yang sangat menganjurkan manusia untuk hidup bersih. Karena kebersihan pangkal kesehatan. ${ }^{(10)}$

\section{b. Pola Makan Yang Sehat}

Salah satu cara yang diajarkan oleh islam untuk meraih kesehatan adalah dengan mengatur pola makan yang baik. Ajaran islam dalam mengelola makan itu ada beberapa hal, diantaranya:

Mengonsumsi makanan yang halal dan baik

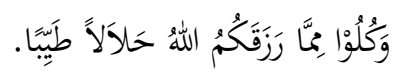

"Dan makanlah dari yang diberikan Allah kepadamu sebagai rezeki yang halal dan baik”. (QS. Al-Ma'idah/5; 8).

Tidak berlebihan dalam makan dan minum.

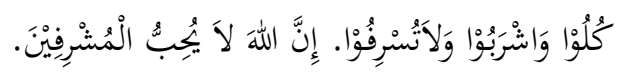

"Makan dan minumlah, tetapi jangan berlebih-lebihan. Sesungguhnya Allah tidak menyukai orangyang berlebih-lebihan”.'(QS.Al-A`raf; 31).

Mengkonsumsi makanan yang bergizi

\footnotetext{
${ }^{7}$ Ali Nurdin. Kesehatan dalam Konsep `(Slide Kuliah 1/10/2012). Jakarta; 2012.hal 25
} 


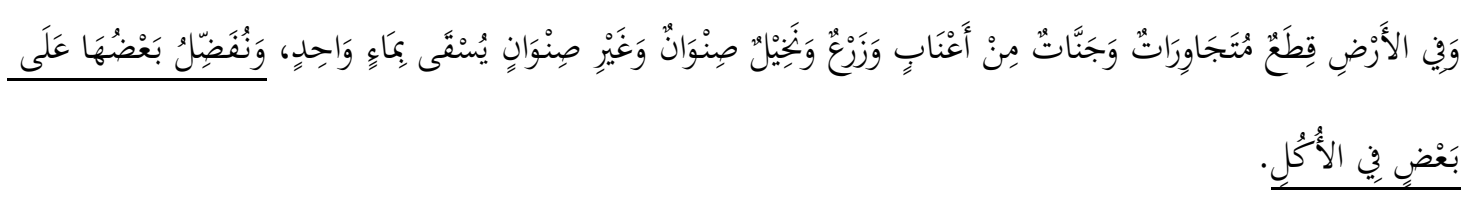

"Dan di bumi terdapat bagian-bagian yang berdampingan, kebun-kebun anggur, tanaman-tanaman, pohon kurma yang bercabang dan yang tidak bercabang, disirami dengan air yang sama, tetapi Kami lebihkan tanaman yang satu dari yang lain dalam hal rasanya”.(Qs. Ar-Ra'd/13; 4).

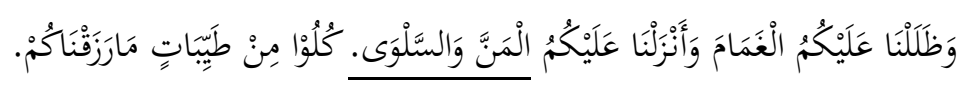

"Dan Kami menaungi kamu dengan awan, dan Kami menurunkan kepadamu mann dan salwa. Makanlah (makanan) yang baik-baik dari rezeki yang telah Kami berikan kepadamu”. ( Al-Baqarah/2; 57).

Tidak makan yang diharamkan.

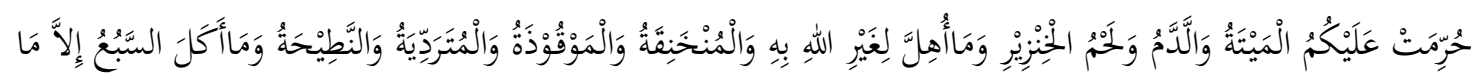

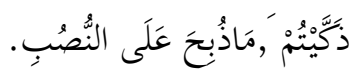

"Diharamkan bagimu (makan) bangkai, darah, daging babi, dan (daging) hewan yang disembelih bukan atas (nama) Allah, hewan yang tercekik, yang dipukul, yang jatuh, yang ditanduk, dan yang diterkam binatang buas, kecuali yang sempat kamu sembelih". (QS. Al-Ma'idah/5; 3).

Tidak mengkonsumsi minuman memabukkan

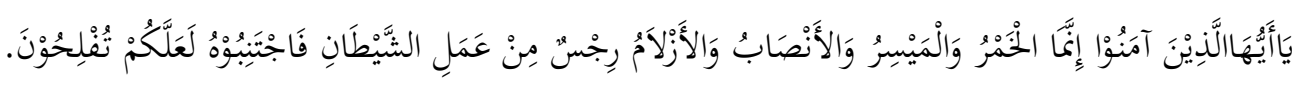

"Wahai orang-orang yang beriman. Sesungguhnya minuman keras, perjudian, (berkurban) untuk berhala, daan mengundi nasib dengan anak panah, adalah perbuatan keji dan termasuk perbuatan setan. Maka jauhilah (perbuatanperbuatan) itu agar kamu beruntung”. (QS. Al-Ma'idah/5; 90).

c. Istirahat Yang Cukup

Allah telah menciptakan pergantian malm dan siang, bukan sesuatu yang tak bermakna. Pergantian ini dimaksud kan adalah untu memberikan kesempatan kepada manusia untuk berusaha pada siang hari dan beristirahat pada malam hari setelah lelah berusaha. Hal ini kembali membuktikan bahwa islam sangat memperhatikan masalah kesehatan. Dalil yang menjelaskan tentang hal ini adalah: 


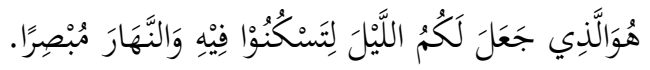

"Dia lah yang menjadikan malam bagimu agar kamu beristirahat padanya dan menjadikan siang terang benderang”. (QS. Yunus; 67).

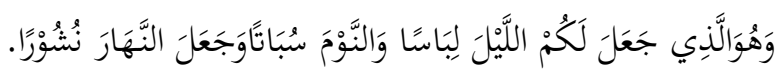

"Dan Dialah yang menjadikan malam untukmu (sebagai) pakaian, dan tidur untuk istirahat, dan Dia menjadikan siang untuk bangkit berusaha”. (QS. AlFurqan; 47).

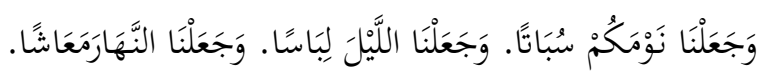

"Dan Kami menjadikan tidurmu untuk istirahat, dan Kami menjadikan malam sebagai pakaian, dan Kami menjadikan siang untuk mencari penghidupan”. (An-Naba'; $9-11)^{(1,2)}$

\section{d. Anjuran Berolahraga}

Islam merupakan agama yang sempurna segala lini kehidupan diatur olehnya, nahkan tentang berolahraga pun ada dijelaskan. Anjuran ini tidak lain agar manusia memilki tubuh yang kuat dan sehat, sehingga dapat optimal beribadah kepada Allah. Dalil yang menjelaskan tentang olahraga antara lain: ${ }^{8}$

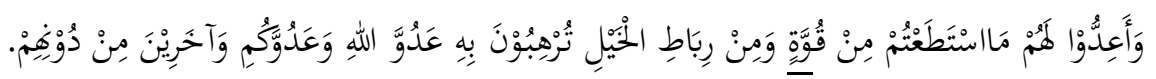

"Dan persiapkanlah dengan segala kemampuan untuk menghadapi mereka dengan kekuatan yang kamu miliki dan dari pasukan berkuda yang dapat menggentarkan musuh Allah, musuhmu dan orang-orang selain mereka”. (QS. Al-Anfal/8; 60).

Rasulullah bersabda:

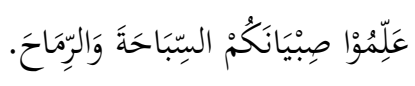

“Ajarilah anak-anakmu berenang danmemanah”.

e. Pencegahan Dan Penyembuhan Penyakit

\footnotetext{
${ }^{8}$ Acmad Gholib. Study Ialam: Belajar memahami Agama, Al-Qur'an, AL-Hadist, dan sejarah peradaban Islam. Jakarta: Faza Media; 2005. Hal 42
} 
Islam juga telah mengajarkan umatnya dalam hal pencegahan dan penyembuhan penyakit. Di antara dalil yang menjelaskan hal tersebut adalah:

Pencegahan

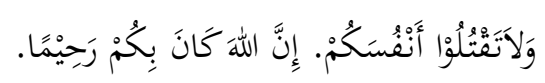

"Dan janganlah kamu membunuh dirimu. Sungguh, Allah Maha Penyayang kepadamu”. (QS. An-Nisa'/4; 29).

Ayat ini turun berkaitan dengan seorang sahabat yang tidak mandi setelah junub, karena cuaca sangat dingin. Ia khawatir bila mandi akan membahayakan dirinya, maka ia hanya melakukan tayamum. ${ }^{9}$

Penyembuhan

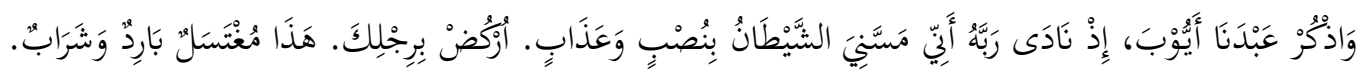

"Dan ingatlah akan hamba Kami Ayyub ketika dia menyeru Tuhannya, 'Sesungguhnya aku diganggu setan dengan penderitaan dan bencana'. (Allah berfirman), 'Hentakkan kakimu, inilah air yang sejuk untuk mandi dan untuk minum”. (QS. Shad/38; 41-42).

\section{Relevansi Ayat Dengan Hadits}

a. Sehatnya Hati, Sehatnya Jasmani

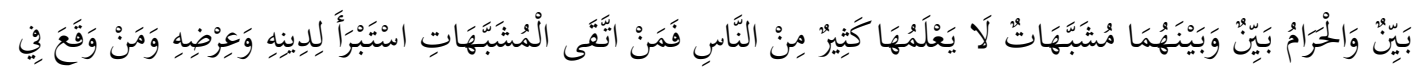

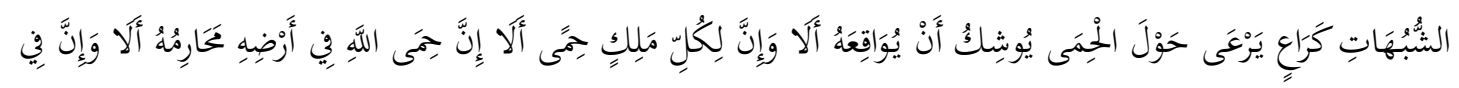

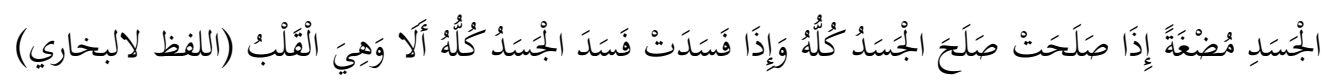

Artinya:

\footnotetext{
${ }^{9}$ Abuddin Nata. Perspektif Islam tentang Pendidikan Kedokteran. Jakarta: FKIK UIN Jakarta; 2004. Hal 12
} 
Dari 'Amir dari Abdullah bin Nu'man bin Basyir r.a. beliau berkata:" Saya mendengar Rasulallah bersabda," sesungguhnya yang halal itu jelas dan yang haram jelas. Di antara keduanya terdapat perkara-perkara yang subhat (samara-samar) yang tidak diketahui oleh orang banyak. Maka siapa yang takut terhadap subhat berarti dia telah menyelamatkan agamanya dan kehormatannya. Dan siapa yang terjerumus dalam perkara subhat, maka akan terjerumus dalam perkara yang diharamkan. Sebagaimana penggembala yang menggembala hewan gembalaannya di sekitar (ladang) yang dilarang untuk memasukinya, maka lambat laun dia akan memasukinya. Ketahuilah bahwa setiap raja memiliki larangan dan larangan Allah apa yang Dia haramkan. Ketahuilah bahwa dalam diri ini terdapat segumpal daging, jika dia baik maka baiklah seluruh tubuh ini dan jika dia buruk, maka buruklah seluruh tubuh; ketahuilah bahwa dia adalah hati. (HR al-Bukhari dan Muslim -redaksi lafazh dari al-Bukhari-) ${ }^{10}$

b. Nikmatnya Sehat

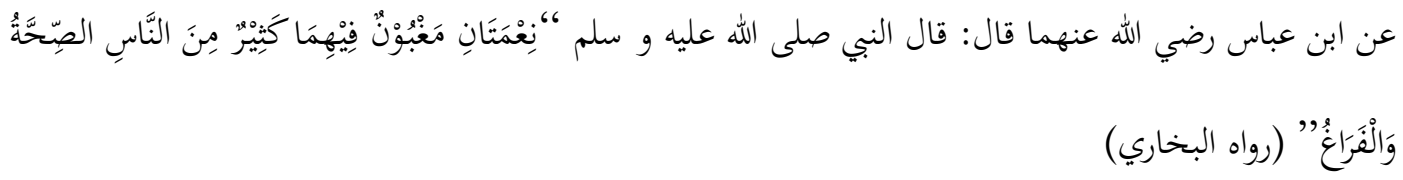

Dari Ibn 'Abbas ra beliau berkata: "Nabi Muhammad SAW bersabda Dua kenikmatan yang dapat memperdaya banyak manusia adalah sehat dan waktu luang "” (HR. al-Bukhari)

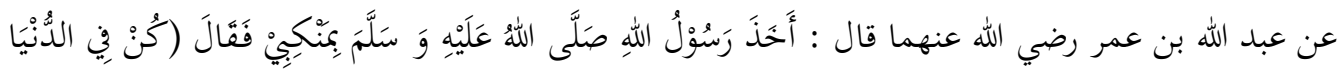

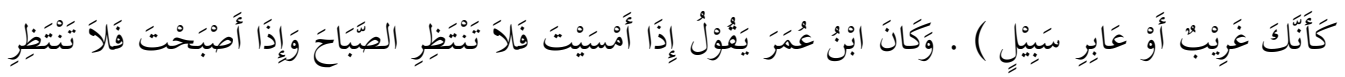

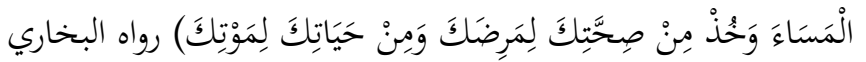

Dari Ibn Umar radliallahu 'anhuma berkata: Rasulullah saw. memegang kedua pundak saya seraya bersabda: "Hiduplah engkau di dunia seakan-akan orang asing atau pengembara," Ibnu Umar berkara: Jika kamu berada di sore hari jangan tunggu pagi hari, dan jika kamu berada di pagi hari jangan tunggu sore hari, gunakanlah kesehatanmu untuk (persiapan saat) sakitmu dan kehidupanmu untuk kematianmu.(HR.al-Bukhari) ${ }^{11}$

\footnotetext{
${ }^{10}$ Achmad Ghalib. Kuliah Kesehatan dalam Persfektif Islam (Slide Kuliah 26/09/2012). Jakarta: 2012.

${ }^{11}$ Ali Nurdin. Kesehatan dalam Konsep `(Slide Kuliah 1/10/2012). Jakarta; 2012. Ha 117
} 
c. Memakan Makanan Yang Baik

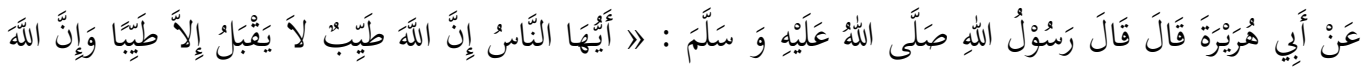

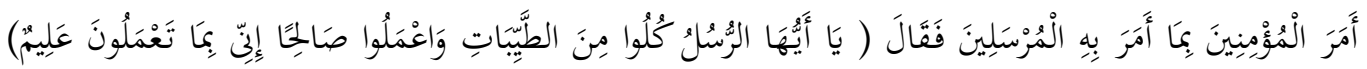

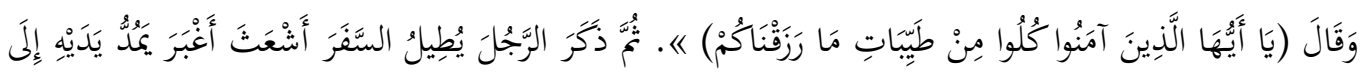

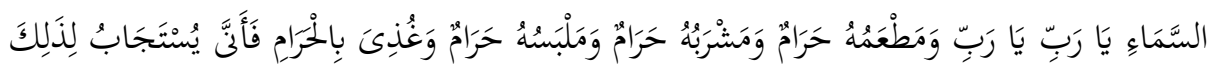

Artinya:

Dari Abu Hurairah r.a. dia berkata: Rasulallah saw. bersabda: Sesungguhnya Allah ta'ala itu baik, tidak menerima kecuali yang baik. Dan sesungguhnya Allah memerintahkan kepada orang yang beriman sebagiamana Ia memerintahkan kepada para Rasul-Nya dengan firman-Nya: "Wahai para Rasul makanlah yang baik-baik dari apa yang Kami rizkikan kepada kalian”. Kemudian beliau menyebutkan ada seseorang yang melakukan perjalanan jauh dalam keadaan kusut dan berdebu. Dia menganngkatkan tangannya ke langit seraya berkata: "Ya Tuhanku, padahal makanannya haram, minumannya haram, pakaiannya haram dan kebutuhannya dipenuhi dari sesuatu yang haram, maka (jika begitu keadaannya) bagaimana doannya akan dikabulkan. (HR. Muslim) ${ }^{12}$

d. Anjuran Berobat

Dari Jabir bin 'Abdullah radhiallahu 'anhu, bahwa Rasulullah Shallallahu 'alaihi wa sallam bersabda:

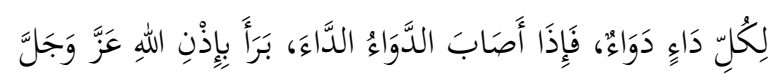

"Setiap penyakit pasti memiliki obat. Bila sebuah obat sesuai dengan penyakitnya maka dia akan sembuh dengan seizin Allah Subhanahu wa Ta'ala.” (HR. Muslim)

Dari Abu Hurairah radhiallahu 'anhu, bahwa Rasulullah Shallallahu 'alaihi wa sallam bersabda:

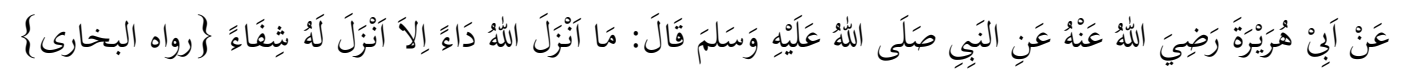

\footnotetext{
${ }^{12}$ Ali Nurdin. Kesehatan dalam Konsep ` (Slide Kuliah 1/10/2012). Jakarta; 2012. Hal 27
} 
Artinya: Abu Hurairoh r.a berkata bahwa rosulullah sallollohu alaihi wassalam bersabda: "Setiap penyakit yang diturunkan oleh Allah pasti dia turunkan juga obatnya". (H.R. Bukhori) $)^{13}$

Dari Usamah bin Syarik radhiallahu 'anhu, bahwa beliau berkata:

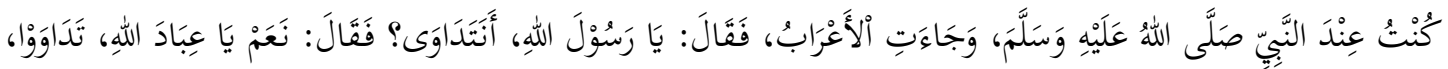

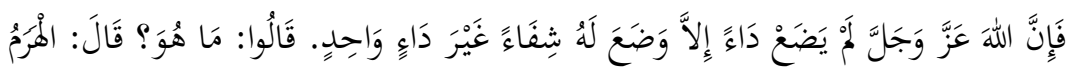

Aku pernah berada di samping Rasulullah Shallallahu 'alaihi wa sallam. Lalu datanglah serombongan Arab dusun. Mereka bertanya, "Wahai Rasulullah, bolehkah kami berobat?" Beliau menjawab: "Iya, wahai para hamba Allah, berobatlah. Sebab Allah Subhanahu wa Ta'ala tidaklah meletakkan sebuah penyakit melainkan meletakkan pula obatnya, kecuali satu penyakit." Mereka bertanya: "Penyakit apa itu?" Beliau menjawab: "Penyakit tua." (HR. Ahmad, Al-Bukhari dalam Al-Adabul Mufrad, Abu Dawud, Ibnu Majah, dan At-Tirmidzi, beliau berkata bahwa hadits ini hasan shahih. Syaikhuna Muqbil bin Hadi Al-Wadi'i menshahihkan hadits ini dalam kitabnya Al-Jami' AshShahih mimma Laisa fish Shahihain, 4/486) ${ }^{14}$

Dari Ibnu Mas'ud radhiallahu 'anhu, bahwa Rasulullah Shallallahu 'alaihi wa sallam bersabda:

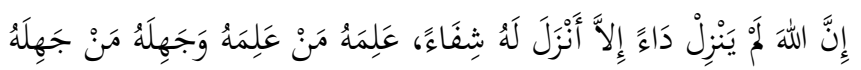

"Sesungguhnya Allah Subhanahu wa Ta'ala tidaklah menurunkan sebuah penyakit melainkan menurunkan pula obatnya. Obat itu diketahui oleh orang yang bisa mengetahuinya dan tidak diketahui oleh orang yang tidak bisa mengetahuinya." (HR. Ahmad, Ibnu Majah, dan Al-Hakim, beliau menshahihkannya dan disepakati oleh Adz-Dzahabi. Al-Bushiri menshahihkan hadits ini dalam Zawa`id-nya. Lihat takhrij Al-Arnauth atas Zadul Ma'ad, 4/12-13)

Rasulullah Shallallahu 'alaihi wa sallam dalam sabdanya:

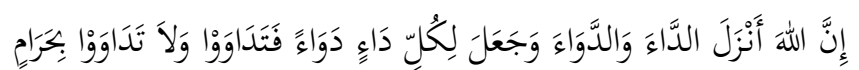

\footnotetext{
${ }^{13}$ Al- albani , m. nasiruddin. Ringkasan shohih bukhari 3\&4 (Jakarta : Gema Insani 2008) no 2226 hal 560

${ }^{14}$ Muqbil bin Hadi Al-Wadi’i Al-Jami’ Ash-Shahih mimma Laisa fish Shahihain, 4/486)
} 
"Sesungguhnya Allah telah menurunkan penyakit dan obatnya, demikian pula Allah menjadikan bagi setiap penyakit ada obatnya. Maka berobatlah kalian dan janganlah berobat dengan yang haram." (HR. Abu Dawud dari Abud Darda' radhiallahu 'anhu)

Abu Hurairah radhiallahu 'anhu berkata:

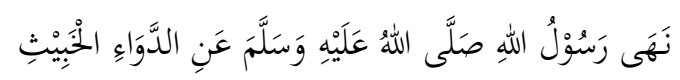

"Rasulullah Shallallahu 'alaihi wa sallam melarang dari obat yang buruk (haram).” (HR. Abu Dawud, At-Tirmidzi, dan Ibnu Majah. Asy-Syaikh AlAlbani menshahihkannya dalam Shahih Ibnu Majah, 2/255) [Lihat kitab Ahkam Ar-Ruqa wa At-Tama im karya Dr. Fahd As-Suhaimi, hal. 21) ${ }^{15}$

Kandungan Ayat

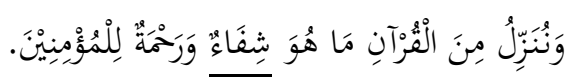

"Dan Kami turunkan dari Al-Qur'an (sesuatu) yang menjadi_penyembuh dan rahmat bagi orang yang beriman”. (QS. Al-Isra'/17; 82).

Ayat ini mengandung sebuah hikmah bahwa al qur'an itu adalah penyembuh obat bagi orang orang mukmin orang mukmin apabila di lantunkan ayat al qur'an akan bergetar hatinya dan bertamba imannya obat bagi jasmani dan rohani dan juga rohmat allah kasih saying allah yang luas untuk orang-orang mukmin, dalam hadis lain Rasulullah Bersabada :

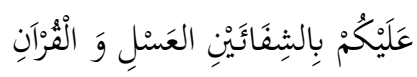

Artinya: kalian harus berpegang teguh pada dua penyembuh yaitu : madu dan al-Qur'an. ${ }^{16}$

Selain itu ada pula hadits yang menjelaskan bahwa penyembuhan dengan menggunakan 2 hal yaitu al-qur'an dan madu.madu juga di sebut sebut sebagai penyembuh penyakit berat, hal itu di kuatkan dengan adanya hadits yang di riwayatkan oleh Abu hurairah yaitu:

\footnotetext{
${ }^{15}$ Dr. Fahd As Suhaimi Ahkam Ar-Ruqa wa At-Tama`im hal. 21

${ }^{16}$ M. Nasiruddin al -abani, ringkasan shohih bukhari vol. 3-4, Jakarta : Gema Insani.2008.
} 


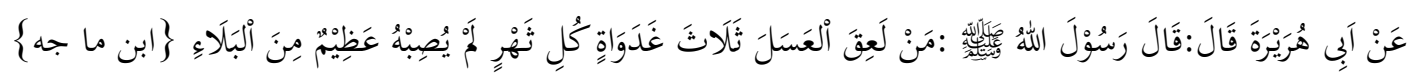

Artinya : "Barang siapa minum madu dalam 3 (tiga) pagi atau 3 (tiga ) kali setiap bulannya maka ia tidak akan di timpa bala' yang berat" (HR. Ibnu majah).

Dengan demikian tidak di ragukan lagi keistimewaan yang terdapat pada madu. Yang mempunyai hasiat medis beberapa kali lipat besar dari pada nilai kulinernya. Fungsi medisnya bagi berbagai organ tubuh, sistem tubuh, dan jaringan tubuh yang sudah terbukti, bahkan hasiatnya di atas batas nalar. ${ }^{17}$

\section{Penjelasan Dan Sarah Ayat}

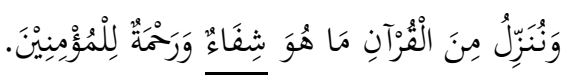

"Dan Kami turunkan dari Al-Qur'an (sesuatu) yang menjadi_penyembuh dan rahmat bagi orang yang beriman”. (QS. Al-Isra'/17; 82).

Thabatthaba'i menjadikan ayat diatas sebagai awal kelompok baru, yang berhubungan dengan awal surah yang menjelaskan keistimewaan al qur'an dan fungsinya sebagai kebenaran nabi muhamad saw. Memang sebelum ayat ini ada beberapa penjelasan di ayat lain tentang al qur'an secara indrawi

Kata syifa' yang bias diartikan kesembuhan atau obat dan digunakan juga dalam arti keterbebasan dalam kekurangan atau ketiadaan aral dalam memperoleh manfaat, sementara ulama memahami bahwa ayat ayat al qur'an sendiri bias menyembuhkan penyakit jasmani

\section{Penjelasan Ayat Dengan Tema Lain}

\section{a. AL-Quwwah (kekuatan)}

Fungsi penciptaan manusia di dunia untuk menjadi khlafah di muka bumi dan beribadah kepada Allah. Namun, dua fungsi penciptaan manusia ini tidak akan terwujud dengan sempurna tanpa adanya kesehatan yang mendukungnya. oleh karena itu,

\footnotetext{
${ }^{17}$ Thayyarah, nadiah. Buku pintar sains dalam al- qur'an "mengerti mukjizat ilmiah firrman allah". (Jakarta ; Dar al-yamamah,2013) Hal-558
} 
Rasulullah bersabda: "Seorang mukmin yang kuat lebih baik dan lebih disayangi Allah daripada mukmin yang lemah” (HR. Muslim). Dan tentunya di dalam al-qur'an pun dijelaskan tentang masalah kesehatn dengan istilah al-quwwah atau kekuatan, seperti:

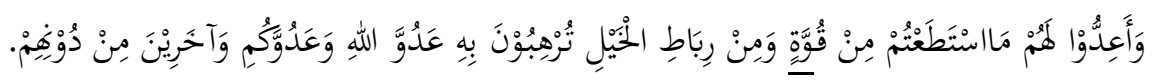

"Dan persiapkanlah dengan segala kemampuan untuk menghadapi mereka dengan kekuatan yang kamu miliki dan dari pasukan berkuda yang dapat menggentarkan musuh Allah, musuhmu dan orang-orang selain mereka”. (QS. Al-Anfal/8; 60). ${ }^{18}$

b. Al-Maradh (sakit)

Tema dalam al-Qur'an yang berkaitan dengan kesehatan adalah al-maradh (sakit) atau lawan dari as-syifa (kesembuhan). Kata sakit yang berhubungan dengan sakit rohani dan jasmani disebutkan dalam al-Qur'an sebanyak 24 kali. Apabila yang dimaksud adalah penyakit rohani, maka digunakan kata al-maradh, seperti:

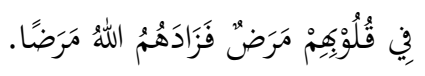

"Dalam hati mereka ada penyakit,) lalu Allah menambah penyakitnya itu”. (QS. Al-Baqarah (2);10).

Apabila yang dimaksud adalah penyakit jasmani, maka biasanya digunakan kata al-maridh, seperti:

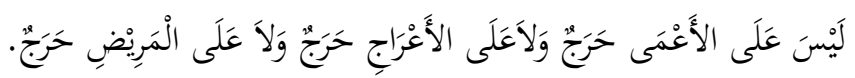

"Tidak ada dosa atas orang-orang yang buta, atas orang-orang yang pincang, dan atas orang-orang yang sakit (apabila tidak ikut berperang)". (QS. Al-Fath/48; 17). ${ }^{19}$

\section{Kesimpulan}

Dari penjelasan diatas, dapat disimpulkan bahwa islam merupakan agama yang sangat kompleks, karena mengatur segala aspek kehidupan baik masalah duniawi,

\footnotetext{
${ }^{18}$ Abuddin Nata. Perspektif Islam tentang Pendidikan Kedokteran. Jakarta: FKIK UIN Jakarta; 2004. Hal 65

${ }^{19}$ Achmad Ghalib. Kuliah Kesehatan dalam Persfektif Islam (Slide Kuliah 26/09/2012). Jakarta: 2012.hal 93
} 
ataupun ukhrawi. Al-Qur'an yang merupakan kalam ilahi dan menjadi pedoman bagi kehidupan manusia mengandung segala ilmu pengetahuan, termasuk ilmu kesehatan.

Kesehatan merupakan hal yang sangat diperhatikan dalam ajaran islam. Karena kesehatan menjadi modal awal untuk beribadah kepada Allah secara optimal. Perhatian islam terhadap kesehatan dibuktikan dengan banyaknya ayat-ayat al-Qur'an dan hadist yang menjelaskan segala hal tentang kesehatan. Oleh karena itu, kita sebagai seorang muslim sudah seharusnya kita mendalami dan mengkaji al-Qur'an yang merupakan pedoman hidup dan sumber segala ilmu pengetahuan. Terlebih bagi seseorang yang berprofesi sebagai dokter muslim, ia harus lebih mengkaji dan mempelajari ilmu-ilmu dalam al-Qur'an, karena segala ilmu pengetahuan, khususnya ilmu kedokteran berasal dari Al-Qur'an dan Hadist.

\section{DAFTAR PUSTAKA}

Ali Nurdin. Kesehatan dalam Konsep `(SlideKuliah,1/10/2012). Jakarta; 2012. Hal 15

Acmad Gholib. Study Islam: Belajar memahami Agama, Al-Qur'an, AL-Hadist, dan sejarah peradaban Islam. Jakarta: Faza Media; 2005. 135

Abuddin Nata. Perspektif Islam tentang Pendidikan Kedokteran. Jakarta: FKIK UIN Jakarta; 2004. Hal 12

Al- Al Bani , M. Nasiruddin. Ringkasan shohih bukhari 3\&4 (Jakarta : Gema Insani 2008) No 2226 hal 560

Budiyanto, B. (2020). Sikap Ilmiah Terhadap Urgensi Hadis Dalam Pendidikan Agama Islam. Al-Bayan: Jurnal Ilmu Al-Qur'an Dan Hadist,3(1), 34-46. https://doi.org/10.35132/albayan.v3i1.83

Departemen Agama RI, Al-Qur`an Al-Karim dan Terjemah Bahasa Indonesia, (Jakarta: Dirjen Binbaga, 2005)

Dr. Fahd As Suhaimi Ahkam Ar-Ruqa wa At-Tama im hal. 21 Muqbil bin Hadi AlWadi 'i Al-Jami' Ash-Shahih mimma Laisa fish Shahihain, 4/486)

M. Nasiruddin al -abani, ringkasan shohih bukhari vol. 3-4, Jakarta : Gema Insani.2008.

Thayyarah, nadiah. Buku pintar sains dalam al- qur'an "mengerti mukjizat ilmiah firrman allah”. (Jakarta ; Dar al-yamamah,2013) Hal-558 